\title{
Formação da rede regional de abastecimento do Rio de J aneiro: a presença dos negociantes de gado \\ (1801-1811)
}

\section{Renato Leite M arcondes}

A amplitude do comércio da carne pode ser avaliada por este defilar ininterrupto deboiadasque perambulam pela colônia [...] Este comércio e consumo de carne relati vamente avultados são propul sores de uma das princi pais ativi dades da colônia: a pecuária; a única, afora as destinadas aos produtores de exportação, que tem alguma importância. Não é com justiça que se relega em nossa história para um plano secundário.[..] Recalcada para o íntimo dos sertões, escondem-na à vista, a intensa vida do litoral, os engenhos, os canaviais, as outras grandes lavouras.

(Caio Prado Jr.)

0

município do Rio de Janeiro representava o principal centro urbano ecomercial brasileiro no início do século XIX, especialmente após a transferência da corte portuguesa em 1808. N este período, a população carioca crescia a taxas significativas, ampliando a demanda de mercadorias. ${ }^{1} 0$ rápido florescimento deste mercado fazia convergir para a cidade uma gama extremamente vasta de produtos nacionais e estrangeiros, que não provinham dos seus arredores. $N$ o plano interno, as relações mercantis al cançavam desde o extremo sul do País até $0 \mathrm{~N}$ ordeste brasileiro, dentro das quais se destacavam as estabelecidas com $M$ inas $G$ erais. 0 abastecimento do Rio de Janeiro fomentava a produção de mercadorias para 0 consumo interno, que no século XVIII supriam as regiões mineratórias.

U ma das principais redes deabastecimento interno ocorria entreo Sul da colônia e o Sudeste. A existência de campos naturais favorecia a criação de gado vacum, cavalar e muar nas áreas sulinas. 0 desenvolvimento da mineração e, posteriormente, das lavouras de cana e do café dinamizou a 
pecuária e a própria rota de comércio, especialmente a partir da abertura do caminho terrestreligando as duas regiões no segundo quartel do século $\mathrm{XVIII} .{ }^{2} \mathrm{O}$ crescimento das necessidades de animais para o transporte, vestuário ealimentação destas economias viabilizava a condução detropas por via terrestre e o envio de couro, sebo, carne seca e charque por via maríti$\mathrm{ma}^{3}$

M ariaT hereza Schorer Petronemostrou o vulto atingido pelo comércio de animais através do caminho do sul a partir de um ponto do eixo mercantil: o registro e a feira de Sorocaba (SP) na década da independência. N estelocal havia um grande número de negócios com animais, seja de vacum, cavalar e, principalmente, muar. A partir das correspondências e, principalmente, dos livros de Antonio da Silva Prado - arrematador do imposto - , a autora pôde calcular o montante de animais que passava pelo registro. ${ }^{4}$ Segundo a autora, estenegócio possibilitou a participação deáreas e pessoas não relacionadas diretamente com a exportação, que não mereceram grande atenção por parte da historiografia:

(...) as correntes de comércio interno, com todas as suas implicações, pouca atenção têm merecido, embora tanto o comércio como a produção de mercadorias a ele destinado representassem para as populações espal hadas pelo interior ou em áreas onde a lavoura de exportação não se estabeleceu um meio de vida apreciável - no caso que nos interessa a criação, condução e comércio do gado. (PETRON E, 1973, p. 383).

A partir de Sorocaba, a rota comercial ramificava-se em vários caminhos, mas com destino às regiões de São Paulo, M inas G erais e Rio de Janeiro. 0 s principais compradores na feira eram oriundos destas áreas. Por outro lado, o abastecimento de animais da corte também ocorria a partir de outras regiões. Além dos oriundos do Sul, também deve-se incluir a oferta de São Paulo e M inas G erais. C omo se verá adiante, grandes áreas destas regiões mantinham atividade de criação de animais.

N este artigo, pretende-se analisar um ponto desta rede de comércio de abastecimento. ${ }^{5} \mathrm{~N}$ a divisa entre São Paulo e Rio de Janeiro, verifica-se um elo significativo de um ramo da corrente de comércio do gado. A conclusão, no final da década de 1770, da estrada ligando a freguesia da Piedade à fazenda Santa C ruz facilitou o deslocamento de mercadorias entre 0 
Rio de Janeiro e São Paulo. Assim, este tronco mercantil ganhou uma via muito superior à trilha do gado anteriormente existente.

0 presente texto está dividido em três partes: a primeira apresenta o estabelecimento da cobrança sobreo gado no caminho entre Rio deJ aneiro e São Paulo ao final do século XVIII; a segunda mostra os volumes de animais al cançados por este comércio e as prováveis fontes de suprimento destes rebanhos vacuns no início do século XIX e, por fim, analisam-se as pessoas envolvidas neste negócio, em especial os principais comerciantes de gado.

\section{I - A taxa sobre o gado}

0 caminho novo da freguesia da N ossa Senhora da Piedadeà fazenda Santa Cruz demandava constantes reparos para a sua conservação. Além das chuvas, um dos principais fatores a dificultar a sua manutenção era 0 significativo trânsito de animais. A construção e a administração da estrada desde a freguesia acima citada até o Rio Piraí encontravam-se sob responsabilidade do capitão-mor da vila de Guaratinguetá ( $M$ anuel da Silva Reis), quese destacou nesta tarefa. Em 1781, o governador da capitania de São Paulo determinou a proibição da passagem de animais pelo caminho novo:

(...) as manadas só poderiam ser conduzidas para o litoral pelo 'caminho do gado' que ficava ao sul do caminho novo. Enquanto a trilha dos bovinos seguia, após transpor o rio do Braço, para Angra dos Reis, a estrada da Piedade dirigia-se para nordeste atéa parte meridional do morro da Fortaleza, ondetomava direção sudesteatéatingir o morro do Frade, continuando com destino a Santa Cruz, via São João M arcos. (Apud REIS, 1971, p. 128)

Em 1794, as reclamações a respeito do péssimo estado da estrada fez com que o Conde de Sarzedas, governador da época, reeditasse a proibição da passagem detropas de animais. As dificuldades de conservação e de controle do uso da estrada, aliada à carência de carne verde no Rio de Janeiro, conduziram à necessidade de estabelecer um novo modo de manutenção que garantisse o bom estado da estrada, sem excluir o gado. A solução encontrada foi a criação de uma taxa sobre o trânsito de animais, de- 
nominada imposição ou contribuição voluntária dos gados que passavam ou entravam pelo caminho novo com destino à corte do Rio de Janeiro. Para cada cabeça estabeleceu-se a cobrança de 80 réis, que foi posta em prática a partir de dezembro de $1801 .{ }^{6}$ Como contrapartida, os moradores ao longo do caminho receberiam a maior parte dos recursos arrecadados a fim de real izarem a sua testada da estrada, sendo esta proporcional à extensão da estrada em suas terras. Eles deveriam utilizar estas quantias para manter o caminho nos seus trechos. D estarte, a menor quantia da taxa do gado comparativamente a outros registros e a possibilidade de reverter 0 valor arrecadado em prol da conservação da estrada deveriam reduzir a sonegação. ${ }^{7}$

Com esta medida, abandonou-se a construção de um novo caminho para o gado pela B ocaina (mel horando a antiga trilha), como se observa na carta do governador Antonio José de França e H orta de 1803 para a Câmara de Lorena, que nesse momento se responsabilizava pela estrada: ${ }^{8}$

(...) visto o mostrarem vossas mercês por uma parte a impossibilidade de se abrir o caminho pela Serra da Bocaina para a passagem dos gados, e pela outra parte a facilidade de se repararem os danos [...] que fez [...] uma vez que toda se descortine, para o que vem a ser o rendimento da imposição, que os boiadeiros preferem pagar, muito superabundantea despesa, queexige o conservá-lo sempre em bom estado. Portanto revogando 0 disposto no relatado ofício, ordeno a vossas mercês, que desistindo do projetado caminho da Bocaina e franqueando outra vez a estrada geral para a passagem dos gados, continue a contribuição antecedentemente imposta, a fim de se poderem fazer efetivamente os consertos e reparos necessários o que essa $C$ âmara executará com todo o zelo, e atividade, que requer e remeterá a esta Secretaria do governo um conta exata, circunstanciada do seu rendimento, edespesa equanto fica restando no cofre, cujo remanescenteo poderão aplicar para a reedificação da matriz desta vila. (Apud REIS, 1971, p. 146)

N os anos seguintes, a C âmara de Lorena enviou quatro prestações de contas referentes aos anos de 1801-1805, 1809, 1810 e 1811 eum grande número de cartas para o governo. ${ }^{9} \mathrm{~A}$ correspondência entre $\mathrm{C}$ âmara e 0 governador permite que se observem outros aspectos da cobrança. Algumas vezes as boiadas eram conduzidas pelo caminho sem as correspondentes guias, o que obrigava o capitão responsável pela administração comu- 
nicar o fato ao governo. Em 1804, Ventura oséde Abreu "suplicantenão só se acha devendo a real fazenda avultada quantia de novos direitos de mil e tantos boisquefez conduzir de Curitiba, para osir dispor na cidade do Rio de Janeiro" (27/05/1804). ${ }^{10}$ Em 1812, o capitão-mor M anuel D omingues Sal gueiro escreveu ao governador $M$ arques de Al legrete a respeito também deste problema e da demanda crescente de animais na corte:

A V Exa neste presente ano, que o Sargento M or Ventura José de Abreu, duvida pagar os 80 réis de cada uma cabeça, fazendo entrar as suas boiadas sem procurar guia do tesouro, e pagar o competente imposto, esse procedimento tem causado al guns boiadeiros pagar o competente imposto de má vontade e para impedir as boiadas a que não passem sem pagar como exige a ordem do Exmo antecessor de V Exmo encontro uma ordem do mesmo Sr de 16/10/1809, que por ordem do intendente geral da polícia Paulo Fernandez Viana, houvesse eu de dar todo auxílio efavor aos boiadeiros para seguirem quanto antes suas boiadas para aquela corte, a fim de não haver faltaaquelegênero em termo devíveressebem queestaordem não derroga aquela imposição voluntária. Esteo motivo de por esta na respeitável presença de Vossa Exa para me determinar o que devo fazer. (AESP, ordens 335 e 336) ${ }^{11}$

A chegada da corte portuguesa provocou uma preocupação adicional com 0 abastecimento do Rio de Janeiro. ${ }^{12}$ Segundo Alcir Lenharo, houve uma série de ordens para "socorrer a cidade demantimentos" (1979, p. 4243). Constatou-se a existência de uma série de correspondências da Câmara para o governador explicando o empenho em fazer conduzir o maior número de tropas de animais para a corte. Em 1808, realizou-se uma relação dosgêneros que se exportaram do distrito da vila de Lorena para a corte do Rio de Janeiro. Entre o mês de maio e de outubro desse ano, os víveres conduzidos foram os seguintes: 1.561 bois, 1 cavalo, 50 porcos vivos, 330 capados, 10.118 galinhas, 1.105 arrobas de toucinho e 4 al queires de farinha. Em novembro de 1809, efetuou-se um levantamento das condições de oferta de bois dos principais negociantes:

Relação das boiadas, invernadas em Taubaté, Bocaina e suas casualidades. 0 capitão Joaquim M oreiradaC osta, tem bois 500 temecarta do D outor Branco que foi ouvidor em Paranaguá para quem a de ter o dinheiro do mesmo gado queo fosseremetendo a determinação do I Imo Intendente G eral da Polícia ejá mandou no Princípio desdemês 200 o resto hádeir indo em levigurando (sic). 
O Sargento M or Ventura José de Abreu tem bois 380 fez seguir no dia 16 deste mês de entregar ao marchante Antonio Ribeiro da Silva 200, o resto fez conduzir a sua fazenda da Bocaina para ali os melhorar e fazer seguir sem maior demora.

José Carlos da Silva tem bois 400

C apitão Brás de O liveira Arruda no dia 25 deste mês chegarão de sua conta 400. (AESP, ordens 335 e 336)

M esmo após o retorno da corte portuguesa, o destino principal do comércio de gado era o município do Rio de Janeiro, pois os rebanhos vacunsfluminensesnão se mostravam suficientes para atenderem à demanda crescente da cidade. A capitaniae, posteriormente, província Rio de Janeiro não mantinha uma pecuária expressiva. Friedrich von Weech, natural da Alemanha, que visitou nosso país entre 1823 e 1827, notou a transformação de uma área de criação da fazenda Santa C ruz para uma área de recuperação dos animais e de controle da oferta para o município: "O utrora também praticou-se a pecuária na fazenda imperial deSanta C ruz (...) Atualmente, o imperador recebe um rendimento considerável dos rebanhos de reses vindos de São Paulo, que permanecem al gumas semanas nos grandes pastos da fazenda para se recuperarem do traslado. [...] A pecuária éexplorada em grande escala nas províncias de São Paulo e M inas Gerais, constituindo um ramo da agricultura muito lucrativo (...)." (WEECH , 1992, p. 163)

John M awe mostra o vulto do trânsito de mercadorias com destaque para o gado - no trecho final do caminho paulista para o Rio Janeiro. Segundo o autor, tais bens originavam-se dos mais diversos locais do centro-sul, à exceção de $M$ inas $G$ erais, que se utilizava de outro caminho no início do século XIX:

(...) entre Sepetiba [RJ] e a Capital. A partir desse ponto, a estrada vai se animando gradualmente, com habitações e plantações, (mas muitas dessas casas são cabanas miseráveis, construídas para a venda de toucinho, milho, bebidas etc.) epor muitos lavradores, trazendo produtos de todas as regiões do Sudoeste, mesmo dos distritosmais remotos de G oiás, C uritiba, São Paulo e M ato Grosso. É comum verem-se oitocentas ou mil mulas, passando e repassando num só dia, além de numerosas manadas de excelentegado para o consumo da cidade. (M AWE, 1978, p. 78-79) 
0 comerciante inglêsJ ohn Luccock esteveentre nós durante o período 1808-1818. Segundo ele, um largo espaço do território brasileiro encontrava-se envolvido neste comércio terrestre de abastecimento, atécerca de 600 a 1.000 milhas do Rio deJaneiro. Do lado "ocidental", a estrada de São Paulo dominava, “(...) [ocupando-se / RLM ] principalmente com 0 transporte de produtos da região setentrional de São Paulo e terras intermédias; mas também já se tem eventualmente trazido por ela gado, mulas e carneiros do Rio-Grande, de distâncias nunca inferiores seiscentas, setecentas e oitocentas milhas" (LU CCOCK, 1951, p. 383). No outro caminho - deM inas Geraispara o Rio deJaneiro - , AugustedeSaint$H$ ilairesalientou, paraum ano um pouco posterior ao ano em questão neste estudo (1816), o porte do comércio de abastecimento interno, no qual também se destacaram as tropas e o gado:

Asestradas vizinhas da capital do Brasil são hojeem dia tão movimentadascomo as que conduzem às grandescidades da Europa. D uranteumas duas léguas não deixamos deencontrar homensa pée a cavalo, enegrosque conduziam descarregados os cargueiros que pela manhã haviam levado à cidade com provisões; rebanhos de bois, e varas de porcos, tocados por M ineiros, avançavam lentamente, fazendo voar turbilhões de pó (...). (SAIN T-H ILAIRE, 1975b, p. 36)

Em outra de suas viagens, 0 autor também ressaltou a importância da rota mineira de abastecimento da corte. Em 1819, ao passar pelo caminho do Rio Preto com destino as M inas, ele afirmou: "É por esse caminho que é transportado quase todo o gado destinado ao Rio de Janeiro e oriundo da parte ocidental da Província de $M$ inas, onde a pecuária é bastante desenvolvida" (SAIN T-HILAIRE, 1975, p. 32). A comarca do Rio das M ortes destacava-se na criação de bovinos: "As excelentes pastagens da região do Rio Grande fornecem hoje $(1819,1822)$ a maior parte dos animais vendidos na capital do Brasil, e al guns criadores locais chegam a possuir até cinco mil cabeças de gado" (idem, p. 50). Por fim, na região de Araxá, o autor observou outra área de criação debois: "(...) vendem evidentemente um bom número de animais, já que, afora a região do Rio Grande, essa partede $M$ inas $G$ eraiséa que fornece o maior número de boisà capital do Brasil" (Idem, p. 126).

D e outro lado, M onsenhor Pizarro comentou nas suas memórias históricas a importância do gado vindo deSão Paulo nessa época: “(...) o gado 
vacum, que em grandes manadas desce a sustentar anual mente de carne verde a capital do Estado e Reino do Brasil (...)." (PIZARRO E ARAÚ JO, 1948, t. I, p. 255) Spix \& M artius ressaltaram, igualmente, a importância desta rota de comércio: "Também atinge grande volume o comércio por terra entre o Rio e as províncias vizinhas, mas particularmente com São Paulo e M inas, até onde levam estradas toleráveis. D o Rio Grande do Sul e deSão Paulo são tocados anual mente muitosmilhares de cabeças de gado para o corte, cavalos e mulas que daqui são espal hados pelas vizinhas capitanias." (SPIX \& M ARTIUS, 1981, vol. I, p. 71). Estas informações permitem vislumbrar as principais rotas de abastecimento de animais vacuns do Rio de Janeiro, dentre as quais o caminho de São Paulo participa de forma destacada pelo menos no início do século XIX.

\section{II - 0 volume de animais e as suas possíveis fontes de suprimento}

As quatro prestações de contas apresentam, de forma discriminada, a passagem das tropas, informando a data, o número de reses, nome da pessoa que pagou a taxa e o total arrecadado. ${ }^{13}$ Por meio destes e de outros informesmaisgenéricos conseguiu-selevantar o número decabeças degado e a arrecadação total da taxa, à exceção de 1807 e 1808. N a Tabela 1 apresentam-se asinformaçõesobtidas. 0 total deanimais registradosalcançou, para os anos disponíveis, quase oitenta mil cabeças, e o valor das taxas pagas al çou a pouco mais de seis contos de réis. $A$ tendência da arrecadação mostrou-secrescenteno período, com apenas uma quebra no ano de 1805. 0 efeito da chegada da corte portuguesa é bastante nítido, uma vez que se constata um aumento, entre 1806 a 1809, de mais de trezentos mil réis, ou quase cinco mil reses. 0 volume de animais para os quais foram pagas as taxas cresceu de quase sete mil animais em 1802 para mais de treze mil em 1811. D estarte, os pedidos dos administradores da capitania eda colônia foram atendidos no seu objetivo de elevar o fluxo de animais para a corte do Rio de Janeiro. 


\section{Tabela 1:}

\section{Arrecadação total e número de reses que pagaram a taxa sobre 0 gado (1801-1811)}

\begin{tabular}{|c|c|c|}
\hline ANO & VALOR ARRECADADO & N ÚMERO DE RESES \\
\hline 1801 & $69 \$ 920874$ & 874 \\
1802 & $544 \$ 560$ & 6.807 \\
1803 & $664 \$ 800$ & 8.310 \\
1804 & $690 \$ 480$ & 8.631 \\
1805 & $476 \$ 160$ & 5.952 \\
1806 & $613 \$ 000$ & 7.663 \\
1809 & $973 \$ 280$ & 12.166 \\
1810 & $1: 072 \$ 720$ & 13.409 \\
1811 & $1: 093 \$ 680$ & 13.671 \\
Total & $6: 198 \$ 600$ & 77.483 \\
\hline
\end{tabular}

Fonte: AESP, O rdens 335 e 336.

0 bs: A arrecadação de 1801 compreen de apenaso mêsdedezembro. A partir defevereiro de 1805 até 0 final do ano de 1806 tem-se apenas o informe do total da receita sem a discriminação por pessoa que pagou a taxa. Por fim, em 1811 acrescenta-se a importância de $139 \$ 760$ rés referentes a 1.747 reses que passaram pelo caminho novo sem guia, mascuja taxa cobrada consta no registro pertencenteao sargento-mor Ventura J osédeAbreu e outros lançados à parte por faltar a guia, mas com taxa cobrada no regi stro.

Pode-se comparar estes números com os levantados por Ângelo Alves Carrara no que diz respeito ao registro da $M$ antiqueira, para o qual existem informações relativas às exportações mineiras direcionadas ao Rio de Janeiro. Esteposto não seencontrava na principal estrada entreM inas G erais e a praça carioca, porém é registrada a passagem de quase catorze mil reses de 1802 a 1811 (CARRARA, 1997, p. 168). D esde a chegada da corte portuguesa houveum aumento do fluxo deanimais deste registro, embora não tão significativo, de 4.745 no período $1804-1806$ para 5.324 animais entre 1809 e 1811. Assim, percebe-se um trânsito bastante expressivo no caminho da Piedade em comparação com o registro da M antiqueira para períodos semelhantes. 
O s documentos compulsados não informam a fonte de suprimento destes animais, ou seja, de quais locais provinham tais tropas. Apesar de se dispor de al guns preciosos dados a respeito da quantidade de animais que passaram por Sorocaba nessa época ("entrados nesta capitania vindos do continente do Sul"), é preciso lançar mão de informações para o período posterior à primeira década do século XIX a fim de complementá-las. 0 governador Antonio $\mathrm{M}$ anuel de $\mathrm{M}$ elo $\mathrm{C}$ astro e $\mathrm{M}$ endonça, em suas memórias sobre a capitania de São Paulo ressaltava a importância do comércio. Ele informou, para 1801, a passagem de 7.053 bestas, 2.148 cavalos, 8 burros e 4.584 bois (CAST RO E M EN D O N ÇA, 1961, p. 77). ${ }^{14}$ Se se comparar os montantes que chegavam a Sorocaba com os que se direcionavam ao R io deJ aneiro pelo caminho da Piedade observam-se duas discrepâncias expressivas: a primeira éreferenteaum total deanimaismenor no tronco de comércio do gado destinado à última região e a segunda relaciona-seà predominância, nesteúltimo caminho, dos animais vacuns em relação aos muares no comércio em Sorocaba.

Esta segunda hipótese parece plausível em razão do uso recorrentedos termos reses, bois e boiadas nos documentos consultados da taxa sobre 0 gado. ${ }^{15}$ Alguns fatores podem ser relacionados para explicar tal fato. $0 \mathrm{~s}$ preços mais elevados dos muares e cavalos em relação aos bois e vacas ajudam a explicar tal resultado. ${ }^{16} 0$ valor agregado inferior produziria um interesse menor na condução destes animais, ou seja, haveria uma preferência pelosmais valiososnestecomércio delonga distância. D eoutra parte, a grande utilidade e demanda dos muares ocorria, principalmente, no interior do país, especialmente em São Paulo e M inas Gerais, para o uso no transporte de cargas pelo vasto território brasileiro, principalmente entre o interior e os portos no litoral. 0 s tropeiros não parecem residir nos centros urbanos, ainda mais no carioca. C omo visto na seção anterior, o município do Rio de Janeiro destacava-se como grande consumidor de carne verde. D estarte, o volume de animais vacuns que transitavam pelo caminho novo da Piedade deveu-se, pelo menos em parte bastante significativa, a animais criados fora do "continente sul". 0 tronco do comércio que passava por São Paulo com destino ao Rio de Janeiro concentrava-se em animais vacuns, na sua grande maioria para o corte. 
Embora o vale do Parába realizasse a criação de gado vacum, a produção de animais do vale não al cançava proporções suficientes para atender à demanda da corte. Em Lorena, o estoque de animais al cançou 1.764 cabeças dos vacum e 308 dos caval ares para o ano de 1798 (cf. M ARCO NDES, 1992, p. 59). N a local idade vizinha de G uaratinguetá, a "produção" deanimais vacum atingiu a soma de 266 cabeças, de cavalar 131 ede muar 33 (cf. COELH O , 1984, p. 27). Com base apenas neste rebanho não seria possível sustentar aquele volume de comércio com o Rio de Janeiro. Vastas áreas de São Paulo e de M inas G erais deveriam participar da oferta de animais vacuns para o Rio de Janeiro, suplementando a oferta sulina e do próprio vale do Paraíba. Ao quetudo indica, entre o final do século XVIII e início do XIX cresceu a importância destas regiões na oferta de animais para o mercado interno da colônia etambém o escoamento dos derivados do gado do Rio Grande do Sul por via marítima. ${ }^{17} \mathrm{Em} 1826$, viajando próximo a Parnaíba (SP), Langsdorff verificou, como ocorria no caminho da Piedade, a condição deteriorada da estrada em virtude do trânsito vultoso de bovinos: "O sanimais não podiam caminhar com passosfirmes, pois os caminhos estavam destruídos em função do grande movimento de tropas de mulas, bois sobretudo, que são levados para o Rio de Janeiro." (SI LVA, 1997, v. II, p. 59). Embora o estudo se refira a um período posterior, 0 comentário de Langsdorff parece pertinentepara a época em estudo, quando aponta o fluxo de animais no interior deSão Paulo direcionados ao Rio de Janeiro.

N essa época, M inas G erais representava o principal centro de abastecimento interno da colônia por via terrestre. Com relação aos vacuns, segundo Eschwege, no ano de 1818/1819 M inas exportou 62.106 cabeças. Se se excluir os animais destinados à Bahia (8.557), chega-se a um total de 53.549 cabeças direcionadas para o Rio de Janeiro. D e acordo com Alcir Lenharo, destetotal, cerca de 10 mil poderiam adentrar o território paulista do Vale do Parába para atingir a corte nesse momento (cf. LEN H ARO, 1979, p. 79-81). A estrada Rio-São Paulo assumia o papel deuma das principais vias utilizadas para o escoamento da produção do sul de M inas:

Concentrava esta via a produção de gêneros que desciam do sul de $\mathrm{M}$ inas e todo o fluxo de mercadorias oriundas de São Paulo, das quais a mais subs- 
tantiva era o gado criado no sul, especialmentenos $C$ ampos $G$ erais. D eacordo com Saint-H ilaire, o movimento principal desta estrada era provocado pelos tropeiros e condutores que provinham do Sul de M inas. [...] Através de um relatório do tenente-engenheiro Conrado ]. N iemayer [de 1829 / RLM ], empenhado nas reformas do leito desta estrada, fica-se sabendo que ela era 'uma das principais estradas, ou talvez a primeira do comércio interior ena qual transitam diariamentemais de 600 animais, cavalos e muares, 300 bois, eimensos porcos, carneiros, cabras...' (LEN H ARO , 1979, p. 62)

Ao analisar a capitania mineira nesse momento, ClotildePaiva destacou a criação de bovinos nas regiões de Sul-central, Sudeste e Sudoeste, as quais poderiam exportar para o Rio de Janeiro partesuas resespor meio do caminho novo da Piedade: "O Sudeste possuía vigorosa atividade comercial, exportava para o Rio de aneiro váriostipos deprodutos sendo os mais importantes os agropecuários: toucinho, bovinos, tabaco, suínos e queijos. [...] As atividades econômicas do Sul Central estavam concentradas na sua parte central, em torno de C ampanha. R egistraram-se a produção de ouro e a presença de grandes fazendas diversificadas. $\mathrm{N}$ ão há informações sobre o comércio intra-regional, apenas referências secundárias ao comércio de bovinos com o Rio de aneiro" (PAIVA, 1996, p. 114 e123). ${ }^{18}$ Cláudia $M$ aria das $G$ raças $C$ haves ressaltou, para a segunda metade século XVIII, a importância da pecuária e do comércio de animaisno interior de $M$ inas: "D e todos os empreendimentos voltados para o mercado interno, a pecuária foi sem dúvida a mais rentável. 0 gado vacum movimentava não apenas o mercado mineiro, mas também as capitanias vizinhas através de um intenso comércio. $\mathrm{H}$ avia grandes criações de gado nas comarcas do Rio das M ortes [que compreende as regiões Sul-central, Sudeste e Sudoeste de ClotildePaiva/ RLM ], Rio das Velhas e Serro do Frio." (1999, p. 97) Em algumas áreas criatórias de $M$ inas não havia a necessidade do fornecimento do sal ao gado, pois as terras continham salitre (cf. SILVA, v. I, 1997, p. 316 e SAIN T-H ILAIRE, 1975, p. 121). Isto reduzia o custo de criação.

U ma ilustração do relacionamento comercial entre São Paulo e M inas podeajudar a confirmar a hipótese de uso do caminho da Piedade para a condução de uma parcela dos rebanhos de M inas para o Rio de Janeiro. Alguns moradores da vila de Santa M aria de Baependi (M G) representaram, com o apoio do capitão-mor M anoel Pereira Pinto, em 1817, a Câ- 
mara da vila de Lorena mostrando a necessidade de conserto do caminho da Serra da M antiqueira. Por tal via realizava-seo escoamento de produtos do sudestemineiro. Segundo as palavras do próprio capitão: “A testo, efaço certo, não só pelas representações, que me têm sido feitas, como pelo pleno conhecimento, que tenho, que a Serra da M antiqueira, por onde transitam numerosas tropas eviandantes para corte do Rio de Janeiro ea cidade de São Paulo se acha incapaz de se passar pelos grandes faltos e desmanchos das cal çadas, quetem motivado grandes prejuízos deanimais, e que não havendo reparo se arruinará a mesma estrada totalmente, e impossibilitará no todo a passagem, e por conseguinte se diminuirão os interesses reais" (AESP, 0 rdem 232). ${ }^{19}$

A condução das boiadas pelos tropeiros para o Rio de Janeiro implicava a existência, ao longo do trajeto, seja a partir do sul da colônia ou de um ponto mais próximo da corte, de uma rede de suporte, compreendendo pastos de invernada ou apenas descanso, ranchos (que fornecem abrigo ealimentação) e pessoas para efetuar o manejo do animais. Adicionalmente, nos elos finais da corrente de comércio também se real izava o controle do fluxo de animais para o Rio de Janeiro, de acordo com os preços vigentesnessa praça. Q uando Antonio da Silva Prado passou a atuar nestenegócio, no quarto lustro do século XIX, percebe-se, por meio de sua correspondência, a sua preocupação em administrar a oferta de animais no mercado carioca. Ele se utilizava das invernadas em Taubaté, Guaratinguetá e Bocaina para regular a oferta na praça carioca, como demonstra a carta a seu sócio Francisco M ariano da Cunha deTaubaté de janeiro de 1821:

0 amigo Tenente João Francisco Vieira [deTaubaté / RLM ] por este próprio me avisa já o gado ter subido de preço no Rio de Janeiro, e por isso talvez seja conveniente fazer marchar para o Rio todo aquele que estiver nos termos disso, mesmo por que com o que segue já não se faz mais despesa, e todo o mais que estiver magro fazer seguir para a Bocaina visto que o capitão Ventura [José de Abreu / RLM ] franqueia todos os pastos pagando-se 200 réis por entrada de cada boi, o que acho caro, por isso seria mel hor um ir tratar com ele próprio, declarando se estiver seis meses um tanto por boi, e se estiver menos tempo, menos do dito [sic], por que talvez as coisas tomem melhor figura, e em pouco tempo nos convenha fazer seguir o gado que ali se vai fazer passar (...).'(Terceiro copiador de cartas 1821-22, p. 2v) ${ }^{20}$ 
Em carta a João Francisco Vieira nesse mesmo dia, Antonio da Silva Prado informava o preço e o montante de animais destinado à invernada: “(...) o capataz do capitão-mor Claudio Ihe dissera já se ter vendido o gado no R io de Janeiro a $10 \$ 200$ parece-meacertado que para lá sigatodo aquele que estiver nos termos disso devendo somente ir para a Bocaina o número de mil a mil e cem daqueles que estiverem mais magros (...)." (Terceiro copiador de cartas 1821-22, p. 3) 0 s termos do negócio também ficavam mais claros na carta ao capitão-mor N uno da Silva Reis, na qual era informado o montante semanal de animais enviados para a corte. Este último efetuava a venda dosanimais no Rio de Janeiro no mês de dezembro de 1821:

Já tem passado 1.600 bois, e ainda conto com 2.000 e tantos, que não tardarão aqui, e por isso deve V. S. contar com perto de 4.000 bois de minha conta, e remessa; e os que aqui tem passado até o presente tem ido gordos, e boa fazenda por que adotei o parecer de V. S. em comprar bois por mais dito como aconteceu; sendo muito de meu agrado, e mesmo conforme $V$. S. me expõem, preferir sempre a fazer a venda de toda a partida ainda com alguma atenção, do que em pontas divididas, e como sei que ao cuidado de V.S. ficatal disposição, não tenho maisa recomendar aV. S., certo queobrará em tudo com a costumeira atividade e só devo dizer aV. S. que no dia 7 do correntejá deTaubaté seguirão 200 bois deminha conta. A serem entregues a V. S., e tendo determinado que todas as semanas siga um igual número e só o deixarei de fazer com o aviso deV. S. que pelo correio vem com brevidade, e quando V. S. ache que pode ir mais também o farei." (Terceiro copiador de cartas 1821-22, p. 134v $)^{21}$

0 grande comerciante não se envolvia diretamente no transporte e venda dos animais. As informações levantadas a partir dos relatos dos viajantes permitiram perceber a larga utilização de capatazes e prepostos para o manejo e a venda do gado. Este fato aponta para a presença de estruturas de comercialização mais complexas e, como se verá adiante, de grandes comerciantes de gado para o Rio de Janeiro, que detinham uma parcela significativa dos montantes transacionados.

\section{III - Os comerciantes do gado}

O comércio de gado atraiu inúmeras pessoas de posses expressivas e, ademais, a sua rentabilidade permitiu ganhos significativos, como no caso 
deAntonio da Silva Prado. ${ }^{22} 0$ papel destacado destes grandes comerciantes também ocorreu em outras áreas do mercado de gado. Cláudia $C$ haves observou, para o interior de M inas G erais na segunda metade do século XVIII, que:

“Para os grandes fazendeiros, ligados principalmente à pecuária, podemos falar em monopólio e estabilidade de mercado, pois, para estes produtores, não havia a incerteza do lucro. 0 fornecimento de gado para corte às grandes povoações era constante e regular, como vimos na região da Comarca do Rio das Velhas. Estes grandes comerciantes, pelo seu predomínio, adquiriram um lugar estabelecido no mercado (...)." (CH AVES, 1999, p. 161)

Saint-H ilaire também notou a importância da figura do comerciante no mercado de gado. Em 1819, 0 autor mostrou a existência de vários intermediários entre o produtor e o consumidor de bovinos: “(...) os negociantes de São João del Rei [comarca do Rio das M ortes/ RLM ] vão todos os anos a Araxá, para comprar gado. Por outro lado, quando fiz o percurso entre Bom Fim eSanta C ruz, arraiais situados no extremo sul da Província de Goiás, encontrei fazendeiros de Araxá percorren do a região e oferecendo diversas mercadorias em troca de bois, que eles levavam para engordar em seus pastos, à espera de que os moradores das vizinhanças viessem comprá-los" (SAIN T-HILAIRE, 1975, p. 183). A rede de comércio parecepermitir uma margem delucro significativa, pois nesseano: “(...) os bois na região do Rio Grande eram comprados a 4.000 réis ( 25 francos) e revendidos no Rio de Janeiro a 7.000" (idem, p. 51). D estarte, como jáavançado por Weech, o comércio de animais propiciava uma rentabilidade elevada. A chegada da corte portuguesa favoreceu a concentração do comércio de abastecimento por meio da presença de intermediários. Segundo Lenharo: "C ada vez mais raros eram os casos de pequenos proprietários que tinham possibilidades de acesso ao mercado, em meio a uma perceptível tendência de concentração do comércio de abastecimento" (LEN H ARO, 1979, p. 46).

O sgrandes mercadorestambém predominavam no transporte do gado para o Rio de Janeiro através do caminho da Piedade. No caso das prestações de contas levantadas, nota-sea presença de 173 negociantes de gado. ${ }^{23}$ A mai oria promoveu a passagem de mais de uma tropa de gado. 0 número total de tropas registradas nas prestações de contas alcançou 819 via- 
gens. D este modo, cada comerciante, em média, teria conduzido quase cinco conjuntos de animais pelo caminho novo. $\mathrm{N}$ a Tabela 2 apresenta-se o número de viagens efetuadas pelos negociantes. A maioria dosmercadores realizou até nove passagens (92,5\% do total), compreendendo $31,5 \%$ das viagens efetuadas e $28,6 \%$ do conjunto de reses. Entretanto, os cinco maiores comerciantes (com 50 ou mais passagens) efetuaram $51,4 \%$ das viagens e conduziram $53,9 \%$ dos animais.

\section{Tabela 2:}

Negociantes, animais e viagens segundo o número de Passagens (1801-1811)

\begin{tabular}{|c|c|c|c|c|c|c|}
\hline \multirow{2}{*}{$\begin{array}{c}\text { PASSAGENS } \\
\text { POR NEGOCIANTE }\end{array}$} & \multicolumn{2}{|c|}{ NEGOCIANTES } & \multicolumn{2}{|c|}{ VIAGENS } & \multicolumn{2}{|c|}{ N ÚMERO DE RESES } \\
\hline & $\mathrm{N}$ úmero & $\%$ & $\mathrm{~N}$ úmero & $\%$ & $\mathrm{~N}$ úmero & $\%$ \\
\hline 1 a 9 & 160 & 92,5 & 258 & 31,5 & 18.466 & 28,6 \\
\hline 10 a 49 & 8 & 4,6 & 140 & 17,1 & 11.322 & 17,5 \\
\hline 50 ou + & 5 & 2,9 & 421 & 51,4 & 34.803 & 53,9 \\
\hline Total & 173 & 100,0 & 819 & 100.0 & 64.591 & 100,0 \\
\hline
\end{tabular}

Fonte: AESP, O rdens 335 e 336.

N ota-sea presença de um número expressivo denegociantes quetransportaram apenas uma vez gado (64,7\% dos comerciantes). Eles conduziram tão-somente $11,5 \%$ das reses e, ao contrário dos grandes mercadores, devem ser produtores que esporadicamente - de forma irregular ofertaram produtos ao mercado. A concentração do comércio do gado nas mãos de uma elite mercantil pode ser percebida, de uma forma diversa na Tabela 3. O s negociantes que transitaram com menos de cem cabeças e, em geral, realizaram uma ou duas passagens constituíam $58,4 \%$ do total de comerciantes, porém transportaram apenas $8,6 \%$ dos animais. D e outro lado, os mercadores que conduziram mil ou mais bovinos representavam apenas 6,3\% do total de negociantes e levavam mais da metade dos animais $(68,6 \%)$. 


\section{Tabela 3:}

\section{Negociantes e animais segundo o tamanho do rebanho dos comerciantes (1801-1811)}

\begin{tabular}{|c|c|c|c|c|}
\hline \multirow{2}{*}{$\begin{array}{c}\text { FAIXAS DE TAM ANH O } \\
\text { DO REBAN HO } \\
\text { POR NEGOCIANTE }\end{array}$} & \multicolumn{2}{|c|}{ NEGOCIANTE } & \multicolumn{2}{c|}{ NÚMERO DE RESES } \\
\cline { 2 - 5 } & N úmero & $\%$ & N úmero & $\%$ \\
\hline 1 a 9 animais & 101 & 58,4 & 5.538 & 8,6 \\
100 a 999 animais & 61 & 35,3 & 14.707 & 22,8 \\
1000 ou +animais & 11 & 6,3 & 44.346 & 68,6 \\
Total & 173 & 100,0 & 64.591 & 100,0 \\
\hline
\end{tabular}

Fonte: AESP, O rdens 335 e 336.

$\mathrm{N}$ a Tabela 4 apresentam-se os principais negociantes de gado que conduziam seus animais pelo caminho da Piedade. A maioria deles mantinha residência no Vale do Paraíba paulista. O s títulos que se seguem aos nomes das pessoas possi bilitam evidenciar a importância dos controladores do comércio na região. O s cinco maiores transportaram, entre os anos de 1801 e 1811, cerca de trinta e cinco mil cabeças, ou seja, cerca da metade dos animais que passaram pela estrada e para os quais foram pagos a taxa do gado.

\section{Tabela 4:}

Os principais negociantes (1801-1811)

\begin{tabular}{|l|c|c|c|c|}
\hline \multicolumn{1}{|c|}{ N EGOCIANTES } & \multicolumn{2}{|c|}{ VIAGENS } & \multicolumn{2}{c|}{ N ú M ERO DE RESES } \\
\hline & N úmero & $\%$ & N úmero & $\%$ \\
\hline Brás de O liveira Arruda, capitão & 120 & 22,3 & 11.108 & 25,1 \\
M anoel José de M elo, capitão & 118 & 21,9 & 8.850 & 20,0 \\
Antonio J osé Ferreira de Abreu, & 70 & 13,0 & 5.260 & 11,9 \\
capitão & & & & \\
Ventura José de Abreu, capitão & 57 & 10,6 & 5.071 & 11,4 \\
José Rodrigues da Silva, alferes & 56 & 10,4 & 4.514 & 10,2 \\
\hline
\end{tabular}




\begin{tabular}{|l|c|c|c|c|}
\hline Luiz Antonio de Carvalho & 37 & 6,9 & 3.147 & 7,1 \\
Lúcio Ribeiro da Silva & 28 & 5,2 & 1.907 & 4,3 \\
M anoel Ribeiro, guarda mor & 15 & 2,8 & 1.148 & 2,6 \\
José G alvão de Siqueira & 14 & 2,6 & 1.129 & 2,5 \\
Antonio Francisco Sardenha, alferes & 10 & 1,9 & 1.126 & 2,5 \\
H ilário G omes N ogueira, capitão & 13 & 2,4 & 1.086 & 2,4 \\
Total & 538 & 100,0 & 44.346 & 100,0 \\
\hline
\end{tabular}

Fonte: AESP, 0 rdens 335 e 336.

É interessante ilustrar as trajetórias dos negociantes de gado com alguns casos mais destacados. Começando pelos comerciantes de Bananal, Brás de O liveira Arruda mantinha laços familiares que 0 auxiliaram a se tornar o maior comerciante dessa época. Seu sogro era H ilário Gomes $N$ ogueira, nascido em Baependi emaior escravista de Bananal no final do século XVIII. A atividade de comércio do gado de Brás deve ter sido influenciada pelo pai. Parecetambém possível que ele tenha assumido os negócios da família. ${ }^{24}$ Segundo N elson N ozoe e José Flávio M otta, o "Sargento-mor Brás de O liveira Arruda [localizado] nas listas nominativas desde 1799, ano em que vivia ainda no domicílio chefiado por seu pai, José Antônio de Oliveira, um criador de gado detentor de 41 escravos, Brás contraiu núpcias em 1804, com D. Alda M aria Floriana N ogueira, uma das filhas do capitão H ilário G omes N ogueira. No ano de seu casamento, possuidor de 31 cativos, Brás Arruda produzia mantimentos, consumidos 'em casa', e comercializava gado com a praça do Rio de Janeiro. 0 café foi produzido pelo domicílio em questão apenasnosanos de1822 e1825 (...)" (NOZOE \& MOTTA, 1999, p. 68). No ano de 1802, Brás de Oliveira Arruda "meteu gado vacum 1.900 cabeças, que vendeu no Rio de Janeiro e lucrou 1:000\$000" e H ilário G omes N ogueira "marcou o presente ano animais vacuns $20 "{ }^{25} \mathrm{H}$ ilário marcou, em 1804, cem animais vacuns, porém vendeu para o Rio quatrocentas cabeças. $\mathrm{N}$ ão parece que sua atividade de criação seja capaz de propiciar um volume de reses de igual monta ao número comercializado. Por fim, este último também chegou a produzir café em 1822. 
A rentabilidade do comércio com o gado oscilava muito de um ano paraoutro. ${ }^{26} \mathrm{~A}$ partir das listas nominativas de habitantes conseguiu-se obter aproximadamente a lucratividade deste negócio para o período anterior à chegada da corte portuguesa. Se em 1802 Brás exportou 1.900 cabeças e lucrou um conto de rés, ele comercializou, no ano anterior, 700 animais vacuns, obtendo $250 \$ 000$ réis de rendimento. Em 1804, Brás vendeu mil cabeças, lucrando apenas $200 \$ 000$. 0 retorno por cabeça deanimal alcançou uma faixa de 200 a 526 réis. Se se aceitar um preço para o gado ao redor de $4 \$ 000$ réis, a taxa de retorno para o comércio do gado estaria em uma faixa de $5 \%$ a $13 \%$. No caso de H ilário, a venda de 400 animais permitiu, em 1804, um ganho de $400 \$ 000$, que possibilitou - mantendo as hipóteses formuladas acima - uma taxa de lucro de 25\%. D estarte, estas cifras fornecem al guns parâmetros acerca da rentabilidade desta atividade, que comparada ao quadro disponível naquelemomento não pode ser considerada desprezível.

$M$ anoel José de M elo morava em Guaratinguetá, mantinha engenho deaçúcar e possuía 32 escravos em 1802. N estecaso, eno ano em questão, o que merece ser destacado éque a sua atividade se concentrava no comércio e não na criação de animais: " $N$ a sua fazenda tem suas criações de que não teve este ano produção e negocia com gado comprado em Curitiba e vendido no Rio de Janeiro que ganhará por ano $200 \$ 000$ pouco mais ou menos". D e acordo com as prestações de contas da taxa do gado, M anoel José de M ello remeteu 243 animais nesse ano e 743 no seguinte. Se 0 envio médio fosse quinhentos animais e o lucro de $200 \$ 000$ réis, a taxa de retorno chegaria, aceitando as hipóteses anteriores, a $10 \%$.

0 utro exemplo degrande comerciante de gado era osé Rodrigues da Silva, natural de Curitiba. Ele se encontrava na vila de Taubaté em 1799, mantendo seis escravos. 0 seu engenho produziu nesse ano 100 arrobas deaçúcar vendidas na paróquia. Ademais, ele "trouxe de Curitiba 800 bois e ainda não vendeu." Seis anos mais tarde, José Rodrigues da Silva tinha elevado sua escravaria para 16 cativos e recebia a designação de Senhor de Engenho. Com relação ao gado, ele comprou 600 bois em Curitiba, mas não lucrou nada, e 700 bestas em que ganhou $800 \$ 000$. N o momento desse recenseamento ele não estava presente por se encontrar em viagem para a sua cidade natal. 
Ventura José de Abreu residia na vila de Lorena. No final do século XVIII, eletrazia fazendas secas do Rio de Janeiro enegociava animais; nesta última atividade chegou a lucrar $200 \$ 000$ réis em 1799 (cf. M ARCO N DES, 1998, p. 282). 0 número de cabeças de gado possuídas por Ventura estava muito aquém do montante comercializado por ano com o Rio de Janeiro. Ele marcou 60 cabeças de gado e 40 de caval os em 1802 e apenas 12 de vacuns e 5 de cavalares em 1817. De outra parte, Ventura comercializou, segundo as prestações de conta, 310 animais em 1803, 450 em 1804, 950 em 1809 e 480 em 1810. Como já observado nos casos descritos acima, os principais controladores do comércio de gado dessa época não criaram animais em idêntica proporção ao montante negociado. 0 acúmulo derecursosno negócio de bovinos permitiu, posteriormente, a mudança de atividade para a agricultura. Eles iniciaram a cafeicultora com cabedais bastante vultosos, o que diminuiu a importância do comércio de gado entresuas ocupações. N estaúltima característica, Venturatambém não foi exceção. A primeira produção decaféanotada ocorreu em 1822, somando 300 arrobas. Pouco antes do seu falecimento, a colheita de café atingiu 2.300 arrobas.

A concentração do comércio de animais mostrou-se, entre esses anos de 1801 a 1811, muito elevada, com um índice de Gini de 0,786.27 Este índice revelou-se superior ao calculado para a propriedade escrava de dez local idades de São Paulo e do Paraná, que se situavam entre 0,44 e 0,54 em 1804 (cf. LU N A \& CO STA, 1983, p. 220). Como os escravos encontravam-se, na sua grande mai oria, alocados nas atividades ligadas à produção, pode-se supor que neste último segmento haveria uma concentração menor do que na comercialização do gado.

Esta evidência pode ser corroborada com os dados levantados por Lucila ReisBrioschi (1991, pp. 277-293) para os criadores de gado em Franca(SP). ${ }^{28} 0$ Assentamento dos $G$ ados originou-se, a partir da criação desta vila em 1824, da necessidade de registrar as marcas do gado dos fazendeiros anotando-se, adicionalmente, o número de cabeças. Entre 1825 e 1830, havia 625 proprietários que possuíam quase quarenta mil animais. A maioria mantinha menos de 50 animais. A concentração da distribuição do gado entre os fazendeiros atingiu um índice de $G$ ini de 0,63 . D e outro 
lado, deacordo com os dados levantados por H elen 0 sório (1999, p. 100) para o Rio Grande do Sul, nota-se um índice de Gini para a distribuição do rebanho vacum em 1784 de $0,716 .{ }^{29}$ D estarte, a desigualdade do lado da criação e produção mostrou-se menor do que na esfera da comercialização.

\section{IV - Considerações finais}

A vital rota de abastecimento do gado apresentava, no início do século XIX, uma vertente importante no caminho da Piedade. Grandes tropas deanimaiseram conduzidas ao Rio dej aneiro por meio desta estrada. Antes mesmo da chegada da corte portuguesa, tal rota assumia um comércio destacado com a praça carioca. D e fato, as demandas das áreas mineratórias, da lavoura da cana e do cafée, em especial, do município do Rio de aneiro formaram uma complexa rede interna de comércio ecriação deanimais, que envolvia um contingente populacional bastante expressivo ao longo das regiões Sul, Sudestee, parcialmente, N ordeste. 0 caminho da Piedade constituía um elo expressivo desta rede interna.

0 vulto atingido por este comércio, principalmente após a chegada da corte portuguesa, favorecia a participação degrandes comerciantes neste negócio, para os quais a atividade de criação assumia, quando ela ocorria, um caráter secundário. Alguns residentes no Vale do Paraíba mais afortunados sobressaíram-se nesta atividade, como, por exemplo, Brás de O liveira Arruda, M anoel José de M elo e Ventura José de Abreu. As possibilidades de acumulação de capitais expressivos nesta atividade despertavam 0 interesse dos detentores de grandes cabedais. De outro lado, 0 empenho de recursos humanos e materiais destas pessoas incrementava os fluxos comercializados.

0 rápido desenvolvimento da economia cafeeira modificaria, a partir da segunda década do século XIX, tal comércio na região do valedo Paraíba paulista ao deslocar a atenção dos grandes mercadores de gado para o ouro verde. Ao que tudo indica, a gestão do negócio com animais demandava grande atenção e viagens constantes que, com o passar dos anos, se mostravam cada vez mais onerosas para os indivíduos já relacionados. Por outro lado, a cafeicultura apresentava uma oportunidadedeganho sem o ônus 
do envolvimento no comércio do gado. ${ }^{30}$ D esta forma, abriu-se, nessa época, espaço para mercadores de outras regiões atuarem neste comércio, como, por exemplo, Antonio da Silva Prado.

Se as informações a respeito da estrutura da posse de cativos de largas áreas do Sudeste brasileiro, levantadas pela historiografia nasúltimas décadas, não revelaram uma concentração tão forte como seria de se esperar e, de outro lado, evidenciaram um grande número de pessoas detendo um, dois, três até cinco cativos convivendo com a plantation, percebe-se um quadro distinto no relativo ao plano mercantil do comércio de abastecimento do gado. ${ }^{31} \mathrm{~N}$ este âmbito, a desigualdade nas atividades mercantis mostrava-se muito superior à da produção. Por outro lado, o porte necessário para a realização do comércio de longa distância limitava o espaço para os detentores de pequenas posses. 0 controle da comercial ização dos bens conduzia a uma diferenciação entre os próprios produtores. À medida que os mai ores agricultores conseguissem atingir mais diretamente seus mercados ou mesmo não se utilizar de intermediários seria possível a eles alcançar um preço mais elevado para seus produtos. ${ }^{32}$ A acumulação de recursos dos comerciantes mostrar-se-ia mais expressiva do que a possibilitada pela faina agrícola. Esta estrutura do mercado colonial de abastecimento favorecia a apropriação de grande parte do excedente gerado por parte de uma reduzida elite mercantil. D esta forma, o potencial do mercado interno colonial manter-se-ia restrito, apesar dos expressivos montantes transacionados no comércio do gado.

\section{Notas}

*Agradeço 0 apoio recebido de Ângelo C arrara, Lélio Luiz de O liveira, M aurício M artins Alves e Paulo M aduro Júnior.

${ }^{1}$ A população da cidade do Rio de Janeiro apresentou um aumento significativo nessa época. Em 1799, somou 43.376 habitantes e atingiu, em 1821, 112.695 pessoas (cf. M ARC O N DES, 1995, p. 255). A taxa geométrica anual média nesse período atingiu pouco mais de $4 \%$ ao ano.

2 Ver PETRO N E (1993), BACELLAR (1994) e LIM A (1982). Vivendo ao longo do caminho entre o Rio Grande de São Pedro e Sorocaba, o capitão-mor Antonio Correa Pinto, fundador da vila de Lages (SC), escreveu ao governador de São Paulo por volta de 1780: “(...) mandar levantar uma povoação no lugar mais conveniente para fazer testa às 
missões espanholas e afugentar a imensidade deíndios que habitam naquelas campanhas, para não infestarem a estrada geral por onde se transitam muitos milhares de caval gaduras e gados cada ano, vindas da campanha do sul para esta capitania ese extraem para as mais do Estado. [...] nunca foi povoada aquela campanha, que não rendendo coisa al guma à Real Fazenda, hojeselamentam os dízimos, os quintos detodos os animais queproduzem as fazendas daquele distrito, anovandosse [sic] cada besta dez tostões e 200 e 300 réis cada rês (...)" (apud C OSTA, 1982, p. 100-101).

${ }^{3} \mathrm{H}$ elen $\mathrm{O}$ sório notou o grande crescimento das exportações do Rio Grande do Sul, especial mente de charque destinado ao comércio interno à colônia do que de couros mais direcionado para o mercado ultramarino entre 1790 e 1821. N esse primeiro ano, o total exportado decharqueatingiu cerca de 200 mil arrobase, no último ano do período referido acima, somou pouco mais de 1,2 milhão (O SÓ RIO , 2000, p. 173). A autora observou ainda as relações entre a economia do Rio G rande e as de exportação: "Se o charque era consumido por um grandenúmero decapitanias, abastecendo a plantation, o trigo destinouse essencial menteao mercado do Rio de aneiro, porto quetambém reexportava os couros à Europa. Em momentos de crise do comércio atlântico, verificou-se que as exportações rio-grandenses tiveram um melhor desempenho do queas do Rio deJaneiro ou mesmo as do Brasil em seu conjunto. Por destinarem-se ao mercado interno colonial, resistiam melhor àscondiçõesinternacionaisadversas, o quevem demonstrar, maisumavez, arelativaautonomia e o dinamismo do mercado interno da América portuguesa" (O SÓ RIO , 2000, p. 297).

${ }^{4} O$ volume total deanimais era de $26.539 \mathrm{em} \mathrm{1820,23.610} \mathrm{em} 1821$ e 30.474 em 1822. (cf. PET RO NE, 1973, p. 393-394). Em sua maioria, estes animais eram bestas (60,5\%, $59,2 \%$ e $68,1 \%$, respectivamentenessesanos). $\mathrm{H}$ erbert K lein notou, com basenos registros dos "impostos debarreira", a preponderância dos muares nas feiras deSorocaba entre 1825 e 1880 (72,3\%, cf. KLEIN , 1989, p. 356). N esta época, o gado do sul parece ter-se direcionado mais para o comércio marítimo de couro, carne-seca, sebo eoutros derivados. Para um análise mais completa do negócio em Sorocaba ver PET RO N E (1976).

${ }^{5} \mathrm{~N}$ este artigo, não foi possível alcançar o comércio nacional de gado. Para as regiões de criação degado não direcionadas ao R io deJaneiro tão-somenterelacionaram-se algumas referências importantes: Silva (1990), M ott (1985) e Falci (1995).

${ }^{6}$ Sese comparar o valor pago neste posto com os registros mineiros da segunda metade do século XV III apresentados por Cláudia M . das G raças C haves (1999, p. 169) percebe-se uma diferença muito grande, pois se cobra, em M inas, $1 \$ 500$ réis por cabeça de gado vacum e $\$ 000$ réis por cavalo ou besta. Segundo Petrone (1976, p. 124), o "novo imposto" de Sorocaba, estabelecido em 1756 e em vigor atéo início do século XIX, chegava a 200 réis por cavalo, 320 réis por muar e 100 réis por cabeça de gado vacum. Em 1824, Langsdorff informava que a alfândega de Paraibuna (divisa entre RJ e M G) cobrava por mula ou cavalo 370 réis (Cf. SILVA, 1997, v. I , p. 368). Saint-H ilaireinformava a respeito da cobrança de uma pataca (320 réis) por boi neste posto em 1819 (Cf. SAIN T-H ILAIRE, 1975, p. 31).

${ }^{7}$ Em 1818, quando Antonio da Silva Prado arrematou os contratos dos impostos de São Paulo, ele chegou a negociar com Ventura José de Abreu os direitos de arrecadação do 
novo imposto das vilas de Lorena e Areias. $\mathrm{N}$ a negociação, um dos argumentos utilizados pelo primeiro era de que Câmara não administrava bem: “(...) vou expor os meus sentimentos a servir-Ihe tão-somente o contrato do novo imposto, dessa vila e Areias 0 presenteano, eo seguintepela quantia de 1:000 $\$ 000$ podeV. S. participar-meparamandarIhe as competentes ordens, pois que tanto ou mais rendeu administrado pela $\mathrm{C}$ âmara, $\mathrm{e}$ bem sabe que nunca administram como um interessado, por que deixam de cobrar de muitas vendas quando as mesmas condições não excetuam quer de vilas, ou, estradas, e atéfazem por menos de $6 \$ 400$ réis quando devo cobrar esta quantia quer tenham um dia, ou um ano (...) (Instituto H istórico e G eográfico de São Paulo. Antonio da Silva Prado, 1 - Copiador, p. 111v.).

${ }^{8}$ A freguesia de N ossa Senhora da Piedade foi elevada à categoria de vila em 1788.

${ }^{9}$ Esta documentação encontra-se depositadano Arquivo do Estado deSão Paulo (AESP), ordens 335 e 336.

${ }^{10} \mathrm{Q}$ uando era capitão, Ventura José de Abreu requereu, em 1817 e 1819, licença "visto quenecessita ele conduzir a sua boiada para aquela cidade [Rio de] aneiro / RLM ] a dispor nela."

${ }^{11}$ Em 1814, 0 então TenenteC oronel $D$ aniel Pedro M üller foi nomeado inspetor da estrada ecom "uma guarda paga na freguesia do Bananal, guarnecida por um cabo edois soldados da ligação desta cidade, para receber as guias do tesouro que acompanha os gados que passam, a fim de não haver extravios." (AESP, 0 rdens 335 e 336).

12 Segundo Petrone, a preocupação com o abastecimento do Rio de Janeiro conduziu também à isenção do imposto de $\mathrm{G}$ arapuava: “C omo se responsabilizasse a $\mathrm{C}$ arta Régia de 1 - de abril pela falta de carneno Rio de aneiro, o imposto foi abolido por outra C arta Régia (15 de setembro de 1809)." (PET RO N E, 1976, p. 143).

${ }^{13}$ Poderia ser questionada se aidentidade do proprietário das tropas era idêntica à da pessoa que recolhia a taxa. Pelo inferido das correspondências, esta semelhança parece-nos aceitável, como visto para os maiores comerciantes.

${ }^{14}$ Licurgo C ostatranscreveu um documento que informava o trânsito numaépoca anterior: "R elação dos animais que passaram pelo Registro de Curitiba vindos do Rio Grande de São Pedro do Sul de bestas, cavalos, éguas, gado e burros nos anos de 1769, 1770 e 1771. N 0 ano de 1769 entraram do Rio G rande de São Pedro do Sul pelo Registro de Curitiba 5.617 cavalos, 1.909 mulas, 67 éguas, 2.047 reses e 3 burros. No ano de 1770 entraram na forma acima dita 5.174 caval os, 2.140 bestas, 2.337 reses. No ano de 1771 entraram na forma sobredita 5.404 caval os, 3.074 bestas, 2.437 reses. Certidão J oséBonifácio Ribas escrivão da fazenda real" (apud CO STA, 1982, p. 173). Em comparação com os dados do governador $\mathrm{C}$ astro $\mathrm{e} M$ endonça, percebe-seum aumento do número de bestase, em menor monta, de reses e, de outro lado, a redução do comércio de cavalos.

${ }^{15}$ Embora os animais cavalares e muares predominem no fluxo comercial, os estoques de vacuns do Sul eram superiores aos dos demais. H oracio Gutiérrez calculou o rebanho existente nas fazendas de gado de C astro e Ponta G rossa (PR) em 1825. D as mais de 36 mil cabeças, $84 \%$ corresponderam ao gado vacum, $12,8 \%$ ao cavalar, $0,4 \%$ ao muar e 
2,8\% ao lanígero (cf. G ALLARD 0, 1996, p. 90). No Rio Grande do Sul, existia, segundo Corcino M edeiros dos Santos, um estoque de 882.332 cabeças em 1787 (cf. SAN TOS, 1984, p. 82-85). D e acordo com D ante de Laytano (1983), o gado vacum respondia, nesse ano, pela maior parcela com 639.164 animais, seguido pelos cavalares (186.470), bois mansos(12.455) emuares (9.371). Por outro lado, H elen O sório informa a existência de 460.856 animais vacuns em 1784 (1999, p. 100). D estarte, as principais exportações do Rio Grande de produtos derivados do gado vacum davam-se por via marítima.

${ }^{16}$ Armênio Rangel, com base nos M apas de Preços das listas nominativas de habitantes, apresenta os seguintes preços médios dos an imais vacuns em 1798 para várias localidades: $4 \$ 000$ para Lorena, $3 \$ 200$ para Pindamonhagaba, $3 \$ 000$ paraTaubaté, $2 \$ 880$ para São Paulo, $2 \$ 500$ para Paranaguá, $2 \$ 400$ para Curitiba e $2 \$ 000$ para Castro. Com relação aosmuares, os valores eram muito superiores: $18 \$ 000$ para Atibaia, $14 \$ 000$ paraB ragança e 12\$000 para Pindamonhangaba eSão Paulo. Por fim, para os cavalares, 0 autor apresenta as seguintes quantias: $10 \$ 000$ em Pindamonhangaba eAtibaia, $8 \$ 000$ em Lorena, $7 \$ 000$ em Taubaté, $6 \$ 500$ em São Paulo, $6 \$ 000$ em Bragança, $5 \$ 000$ em Sorocabae el tapetininga, $4 \$ 000$ em Itapeva, Curitiba e C astro. (RAN G EL, 1990, p. 366). O s preços na região da futura província do Paraná são inferiores aos do Vale do Paraíba, justificando o fluxo entre as duas regiões. $\mathrm{N}$ o M apa Final dePreços de Lorena verifica-se um preço médio da cabeça de gado vacum de três mil réis, enquanto o cavalar atingia dez mil réis para o ano de 1799 (Cf. M ARCON DES, 1992, p. 108). O s preços, em termos absolutos, oscilavam muito deum ano para o outro, masa proporção entreeles mantinha-semais ou menossemelhante. D eoutro lado, segundo Petrone, os preços para a década de 1820 de $6 \$ 000$ réis para o boi e de $14 \$ 000$ a $20 \$ 000$ réis para as bestas (cf. PET RO N E, 1973, pp. 398-399). Assim, nota-sequeo preço superior para os animais cavalares emuaresera superior aos dos vacuns. ${ }^{17}$ Saint-H ilaire, visitando C uritiba, informava: "O s negociantes vão buscar os bezerros nas fazendas, os quais em sua quase totalidade são vendidos no Rio de Janeiro. Alguns anos antes da minha viagem [1820] e quando ainda se levava o gado do Rio Grande do Sul para a capital (...)." (1978, p. 19)

${ }^{18}$ Raimundo da Cunha M atos, em sua Corografia de M inas G erais de 1837, afirmava que os lavradores mineiros não se preocupavam tanto com a criação de cavalos e muares em relação aos bovinos: “É mui grande a criação do gado vacum da província; a estatura dele não passa de mediana quando se confronta com a do gado das províncias do sul [...] 0 Rio deJ aneiro consomea maior partedo gado nascido na província" (CU N H A M ATOS, 1981, p. 306).

${ }^{19}$ É bastante esclarecedora a passagem do livro Viagem pelo Brasil (1817-1820), de Spix e $M$ artius, a respeito deste caminho: “O comércio principal deSão Paulo para M inas consiste em mulas, cavalos, sal, carneseca, ferragens etodos os demais produtos defabricação, que costumam ser despachados da costa para o interior. (...) M inas despacha, sobretudo, tecidos de algodão grosseiro para a capitania de São Paulo" (SPIX \& M ART IUS, 1981, vol. I, p. 123). Em outro trecho, adicionavam-seoutros produtos na pauta de exportação deM inas: fumo e café (cf. idem, p. 71). 
${ }^{20}$ A correspondência de Antonio da Silva Prado encontra-se disponível no Instituto H istórico e G eográfico de São Paulo.

${ }^{21} \mathrm{O}$ s negócios com bestas também ocorrem, mas por intermédio da análise das correspondências não parece que os montantes sejam equivalentese, em geral, com pessoas de São Paulo e M inas G erais.

22 Petrone estimou lucros de $28,3 \%$ a $64,2 \%$ sobre o capital empatado no comércio do gado de $\mathrm{C}$ ampos $\mathrm{G}$ erais ao Rio de Janeiro durante a década da independência (cf. PETRONE, 1973, p. 404).

${ }^{23} \mathrm{~N}$ ão foi considerado, nesta seção, o período de fevereiro de 1805 a dezembro de 1806 por falta da informação por negociante. D e outro lado, os 1.747 animais de propriedade deVentura José de Abreu e outros (não informados no documento) foram considerados como sendo apenas do primeiro.

${ }^{24} \mathrm{~A}$ existência desociedadeentre parentes eamigos parece usual. Em Taubaté, João Gomes de Araújo - de idade de 28 anos - foi anotado na lista de 1805 como negociante: "comprou em Curitiba a várias pessoas de sociedade em seu pai o sargento-mor Eusebio José de Araújo e o alferes J oséAntonio N ogueira 3 mil bois por 14:000\$000 réis, os quais se acham extraindo na cidade do Rio deJ aneiro." Estejovem negociante chegou a conduzir tropas pelo caminho da Piedade, somando 524 reses de 1803 a 1805, posteriormentenão foi mais localizado.

${ }^{25}$ As listas nominativas de habitantes de Lorena, Taubatée G uaratinguetá encontram-se depositadas no AESP. Brás chegou a comercializar, segundo este documento, quatro mil cabeças de gado em 1816. Posteriormente, esta atividade desaparece do rol de ocupações de sua família.

${ }^{26} \mathrm{~N}$ as listas deTaubatéfoi localizado um caso interessante. Em 1805, José Pereira Q uadra - nascido em Curitiba - foi recenseado como negociante de gado e mantinha onze cativos, com o seguinte adendo: "nas boiadas compradas o ano passado em Curitiba que extraiu no Rio de Janeiro teve prejuízo grande." Entretanto, apesar do prejuízo, ele "comprou este ano ao sargento-mor João Afonso em Itapetininga 300 bois que se acham por extrair." Tal exemplo ajuda a demonstrar o risco da atividade de comércio de gado ea pequena acuidadedestas cifras, especial mente as referentes à lucratividade. D eoutro lado, no ano de 1808, este negociante de boiadas encontrava-se em Curitiba e tinha levado consigo alguns de seus escravos: "falta seus escravos André, D omingos e I gnácio que os levou para vender na vila de Curitiba." Por fim, ele perseverava nesta atividade, pois em 1815 tinha comprado em Curitiba 800 bois, mas os estava devendo e "não sabe o que ganhará."

${ }^{27}$ Se se desconsiderar as 1.747 reses de Ventura, o índice de Gini será de 0,781.

${ }^{28}$ Esta região sobressaía-sena criação de gado em São Paulo. 0 s comerciantes de São J oão del Rei realizavam freqüentemente compras de animais nesta área, especialmente dos pequenos fazendeiros. Segundo Saint-H ilaire: "O s fazendeiros aproveitavam-se das excel entes pastagen squeo lugar oferece, dedicando-seà criação de ovel has edenumeroso gado, não negligenciando também a de porcos. O s mais ricos enviam as suas crias, por 
sua conta própria, à capital do Brasil, e os negociantes da Comarca de São João del Rei vão comprar nas próprias fazendas o gado dos criadores menos prósperos" (SAIN TH ILAIRE, 1976, p. 92).

${ }^{29} \mathrm{O}$ cálculo do Gini efetuado acima foi realizado a partir dos informes do número de pessoas presentes em diversas faixas de tamanho dos rebanhos (1 a 100, 101 a 500, 501 a $1.000,1.001$ a 2.000 e mais de 2.000 cabeças) e o número médio de animais em cada faixa. D estarte, o valor calculado desta forma mostra-se mais aproximativo do que os demais.

${ }^{30}$ Como visto na correspondência de Antonio da Silva Prado, Ventura José de Abreu e $M$ anoel José de M elo tornaram-se, além de senhores de engenho e cafeicultores, no final da segunda década do século XIX, rentistas dos seus campos, arrendando seus pastos para o gado de terceiros.

31 Para uma anál ise mais sistemática da produção historiográfica sobre estrutura da posse de cativos, ver M OTTA (1999).

${ }^{32} \mathrm{U}$ m outro caso defavorecimento dosgrandes detentores de recursosem relação aos demais na comercialização de bens pode ser observado na economia cafeeira do vale do Paraíba paulista no início do século XIX. O s pequenos cafeicultores não conseguiam alcançar diretamente a praça carioca e, por isso, sesujeitavam a intermediários(ver M ARCO N DES \& M OTTA, 1999).

\section{Referências bibliográficas}

BACELLAR, Carlos de Almeida Prado. Família e sociedade em uma economia de abastecimento interno (Sorocaba, século XVIII eXIX). Tese (D outorado em H istória) - FFLCH -USP, 1994.

BRIOSCHI, Lucila Reis et alii. Entrantes no sertão do Rio Pardo: o povoamento da freguesia de Batatais século XVIII eXIX. São Paulo: CERU , 1991.

CARRARA, Ângelo Alves. Agricultura e pecuária na capitania de M inas Gerais (1674-1807). Tese (D outorado em H istória) - IFCS/U FRJ, 1997

CH AVES, Cláudia M aria das Graças. Perfeitos negociantes: mercadores das minas setecentistas. São Paulo: Annablume, 1999.

COELH O, Lucinda Coutinho de M ello. Ensaio socioeconômico de áreas valeparaibanas. Rio de Janeiro: Asa Artes Gráficas, 1984.

COSTA, Licurgo. 0 continente das Lages: sua história einfluência no sertão da terra firme. Florianópolis: Fundação C atarinense de Cultura, 1982.

CUN H A M ATOS, Raimundo José da. Coreografia histórica da Província de M inas Gerais (1837). B elo H orizonte/São Paulo: Itatiaia/Edusp, 1981. 
FALCI, M iridan Britto Knox. Escravos do sertão: demografia, trabalho e relações sociais. Teresina: Fundação Cultural M onsenhor Chaves, 1995.

G ALLARD O , D ario H oracio G utiérrez. Terrasegado no Paraná tradicional. Tese (D outorado em H istória) - FFLCH -USP, 1996.

KLEIN , H erbert S. A oferta demuaresno Brasil C entral: o mercado deSorocaba, 1825-1880. Estudos Econômicos. São Paulo, v. 19, n. 2, pp. 347-372, mai./ ago. 1989.

LAYTAN O , D ante de. O rigem da propriedadeprivada no Rio Grandedo Sul. Porto Alegre: M artins Livreiro, 1983.

LEN H ARO , Alcir. As tropas da moderação: 0 abastecimento da corte na formação política do Brasil: 1808-1842. São Paulo: Símbolo, 1979.

LIM A, Enezila de. A vila de Curitiba: 1765-1820: estudo da dinâmica econômicasocial de uma comunidade. Tese (D outorado em H istória) - FFLCH -U SP, 1982.

LU C CO CK, John. N otas sobre o Rio de Janei ro e partes meridionais do Brasil: tomadas durante uma estada de dez anos nesse país, de 1808 a 1818. 2ª edição. São Paulo: Livraria M artins, 1951.

LUN A, Francisco Vidal \& COSTA, Iraci del N ero da. Posse de escravos em São Paulo no início do século XIX. Estudos E conômicos. São Paulo, v. 13, n. 1, pp. 211-221, jan./abr. 1983.

M ARCO N DES, R enato Leite. D esenvolvimento da produção e comportamento dos preços na constituição da economia cafeeira lorenense. M onografia ( $G$ raduação em Economia) - FEA/U SP, 1992.

M ARC O N DES, Renato Leite. 0 evolver demográfico e econômico nos espaços fluminenses (1780-1840). Estudos Econômi cos. São Paulo, v. 25, n. 2, pp. 235-270, mai./ago. 1995.

M ARCON DES, Renato Leite. A arte de acumular na economia cafeeira: Vale do Paraíba, século XIX. Lorena: Editora Stiliano, 1998.

M ARC O N DES, Renato Leite\& M OTTA, JoséFlávio. Preçose comercial ização do café no vale do Paraíba paulista: Bananal em inícios do século XIX. Re vista Brasileira de Economia, Rio de Janeiro, v. 53, n. 2, pp. 183-209, abr./ jun. 1999.

M AW E, John. Viagens ao interior do Brasil. Belo H orizonte/São Paulo: Itatiaia/ Edusp, 1978. 
M OT T, Luiz R oberto de Barros. Piauí colonial: população, economia e soci edade. Teresina: Projeto Petrônio Portella/Fundação Cultural do Estado do Piauí, 1985.

M OTTA, José Flávio. The historical demography of Brazil at the $V$ centenary of its discovery. Ciência e Cultura: Journal of the Brazilian Association for the Advancement of Science. São Paulo, v. 51, n. 5/6, pp. 446-456, set./dec. 1999.

N OZOE, N elson \& M OTTA, JoséFlávio. O sprodutores eventuais de café: nota sobre os primórdios da cafeicultura paulista (Bananal, 1799-1829). Locus: Revista de H istória. Juiz de Fora, v. 5, n. 1, pp. 51-84, 1999.

O SÓ RIO, H elen. Estancieiros, lavradores e comerciantes na constituição da estremadura portuguesa na América: Rio Grande de São Pedro, 1737-1822. Tese (D outorado em H istória) - ICH F/UFF, 1999.

PAIVA, Clotilde Andrade. População e economia nas M inas Gerais do século XIX. Tese (D outorado em H istória Social) - FFLCH /U SP, 1996.

PET RO N E, M aria T heresa Schorer. 0 afluxo de gado a Sorocaba e a importância econômica do caminho do sul na década da independência. Revista de H istória. São Paulo, v. XLVI, n. 94, ano XXIV, pp. 383-406, abr./jun. 1973.

PETRONE, M aria Theresa Schorer. 0 Barão de I guape. São Paulo: N acional. Brasília: IN L, 1976.

PET RO N E, M ariaT heresa Schorer. Asáreas decriação degado. In: H O LAN D A, Sérgio Buarque de (ed.). H istória geral da civilização brasileira. 7ạ edição. Rio de Janeiro: Editora Bertrand Brasil, 1993, tomo I, 2ํvolume, pp. 218227.

PIZARRO E ARAUJO, José de Souza Azevedo. M emórias históricas do Rio de Janeiro. Rio de Janeiro: Imprensa N acional, 1948, 8 v.

PRAD O JR., Caio. Formação do Brasil contemporâneo: colônia. São Paulo: Brasiliense/Clube Folha, 2000.

RAN GEL, Armênio deSouza. Escravi smoeriqueza: formação da economia cafeei ra no município deTaubaté(1765-1835). Tese (D outorado em Economia) FEA/USP, 1990.

REIS, Paulo Pereira dos. 0 caminho novo da Piedade no nordeste da capitania de São Paulo: apontamentos para o estudo do 'caminho novo da freguesia de N ossa Senhora da Piedade à fazenda Santa Cruz dos padres jesuítas (1725-1822). São Paulo: Conselho Estadual da Cultura, 1971. 
SAIN T-H ILAIRE, Auguste de. Viagem às nascentes do rio São Francisco. Belo H orizonte/São Paulo: Itatiaia/Edusp, 1975.

SAIN T-H ILAIRE, Auguste de. Viagem pelas províncias do Rio de Janeiro e M inas Gerais. Belo H orizonte/São Paulo: Itatiaia/Edusp, 1975b.

SAIN T-H ILAIRE, Auguste de. Viagem à província de São Paulo. Belo H orizonte/São Paulo: Itatiaia/Edusp, 1976.

SAIN T-H ILAIRE, Auguste de. Viagem a Curitiba eprovíncia deSanta Catarina. Belo H orizonte/São Paulo: I tatiaia/E dusp, 1978.

SILVA, D anuzio Gil Bernardino da (org.). Os diários de Langsdorff. Campinas/ Rio de Janeiro: Associação Internacional de Estudos Langsdorff/Fiocruz, 1997, 3 v.

SILVA, Francisco C arlosTeixeira da. A morfologia da escassez: crise de subsistência epolítica econômica no Braśl colônia (Salvador - Rio deJaneiro, 1680-1790). Tese (D outorado em H istória) - ICH F/U FF, 1990.

SAN TOS, Corcino M edeiros. Economia e sociedade no Rio Grande do Sul: século XVIII. São Paulo: Companhia Editora N acional, 1984.

SPIX, Johann Baptistevon \& M ARTIUS, Carl Friedrich Phillip von. Viagem pelo Brasil: 1817-1820. Belo H orizonte/São Paulo: I tatiaia/ED U SP, 1981, 3 v.

WEECH , J. Friedrich von. A agricultura eo comércio do Brasil no sistema colonial. São Paulo: M artins Fontes, 1992.

\section{Resumo}

N este arti go procura-se analisar o comércio de abasteci mento interno no início do sé culo XIX. 0 segmento estudado é o mercado de gado para o Rio de Janeiro, com base nos registros de cobrança de uma taxa sobre os animais no caminho entre São Paulo e - Rio Janeiro. 0 desenvolvimento do núcleo urbano carioca, principal mentea partir da chegada da corte portuguesa, demandava expressi vosfluxos demercadoriasatravés desta rota. Entretanto, mesmo antes da vinda da corte tal abastecimento ocorria em montantes consideráveis. Por fim, nota-se que o controle do comércio de animais encontrava-se concentrado nas mãos de poucos mercadores.

\section{Abstract}

The purpose of this paper isto analyze the col onial internal trade at the beginning of the nineteenth century. The market segment focused in the study is the cattle trade to 
Rio de Janeiro, based on a tax charged for the animals on the way from São Paulo to Rio deJaneiro. Thegrowth of thecity of Rio de Janeiro, mainly after the arrival of the Royal Court from Portugal, required a significant increasein theflow of goods on that route. $\mathrm{H}$ owever, even beforetheC ourt'sarrival themarket wasal ready very expressive. Finally, thestudy also showsthat cattletrading wasa businessin thehands of a merchant elite. 